DOI: $10.7242 / 1998-2097 / 2018.4 .3$

УДК 535.015

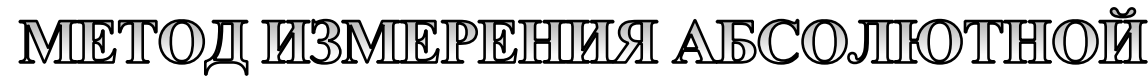

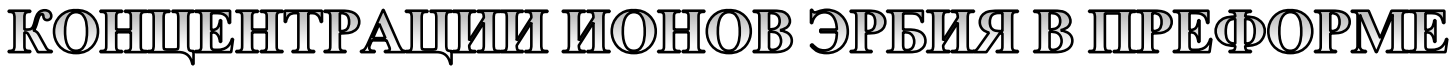

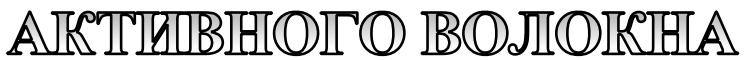

К.П. Латкин, Пермский федеральный исследовательский иентр УрО РАН; Пермский наииональный исследовательский политехнический университет

А.С. Смирнов, Пермский федеральный исследовательский центр УрО РАН; Пермский национальный исследовательский политехнический университет

Ю.А. Константинов, Пермский федеральный исследовательский центр УрО РАН

В.В. Бурдин, Пермский федеральный исследовательский центр УрО РАН; Пермский национальный исследовательский политехнический университет

Активные волоконные световоды применяются в качестве активной среды в оптических волоконных усилителях и лазерах. Концентрация активной примеси в сердцевине волоконного световода есть их основная характеристика, которая определяет основные параметры будущих лазеров и усилителей. В работе предложен метод измерения абсолютной концентрации активной примеси в преформе (заготовке) активного волоконного световода. Метод, основанный на измерении интенсивности люминесценции активной примеси, рассматривается на примере преформы легированной ионами эрбия. Излучение, возбуждающее люминесценцию, имеет длину волны 980 нм и направлено вдоль оси преформы. Люминесценция наблюдается в спектральной области 1,50-1,55 мкм. Регистрация интенсивности люминесценции производится с боковой поверхности преформы. В работе приведена рабочая фрормула расчета абсолютного значения концентрации активного элемента, в частности ионов эрбия. Дана оценка чувствительности метода к различным концентрациям активной добавки. Приведены рассуждения о чувствительности метода к стабильности источника излучения. Данные измерения позволяют анализировать и контролировать процесс производства преформ активных волоконных световодов, прогнозировать концентрацию легирующего активного компонента и его однородность вдоль длины световода, полученного при вытяжке из исследованных преформ.

Ключевые слова: эрбий, активные волоконные световоды, анализ конщентрации, преформа, заготовка оптического волокна, спектр люминесиенции, метрология.

\section{Введение}

Активные оптические эрбиевые волоконные световоды находят широкое применение в производстве волоконных источников излучения, в том числе лазеров [1] и усилителей, поскольку длина волны люминесценции ионов эрбия (1,53 мкм) попадает в окно прозрачности кварцевых оптических волокон. Одним из важнейших свойств активных волокон является концентрация активных ионов, от которой зависят усилительные свойст- 
ва активной среды будущих волоконных усилителей или лазеров. Основные качества будущего оптического волокна будет определять преформа (заготовка) длиной несколько десятков сантиметров, в процессе вытяжки которой происходит уменьшение радиуса и соответствующее удлинение, в конце чего получается нитеподобный конечный продукт.

Таким образом, контроль концентрации активных ионов необходимо осуществлять еще на стадии производства преформ. Круг методов измерения концентрации активных ионов достаточно ограничен, и разработка простого, быстрого метода является актуальной темой для исследований. Существуют оптические методы, в которых концентрация активных ионов определяется по интенсивности люминесценции - процесса спонтанного испускания света ионами эрбия, предварительно переведенных в возбужденное состояние.

В работах $[2,3]$ был предложен метод контроля однородности концентрации ионов эрбия в преформах. Для накачки заготовок использовался лазерный диод с длиной волны 980 нм. Накачка производилась через боковую поверхность заготовки. В каждый момент времени возбужденным оказывался только небольшой участок преформы. По интенсивности спектра люминесценции концентрация ионов эрбия определялась в относительных единицах, т.е., по сути, лишь сравнивались концентрации эрбия в различных сечениях вдоль длины заготовки. Для определения же абсолютных значений концентраций данным методом необходимо использовать калибровочную заготовку с известной концентрацией эрбия. Это существенно увеличивает время измерений и вероятность случайной ошибки, поскольку мощность лазерного диода может изменяться с течением времени. Приходится решать непростую проблему стабилизации и контроля мощности лазерного диода.

В данной работе поставлена задача разработать метод измерения абсолютной концентрации ионов эрбия без использо- вания калибровочной заготовки, требующий существенно меньшего времени измерений, в течение которого мощность диода накачки можно было бы надежно считать постоянной.

\section{Обсуждение метода измерения концентрации эрбия}

Пусть сердцевина активной заготовки из алюмосиликатного стекла с ионами эрбия облучается светом интенсивности $I$. Если определять концентрацию эрбия $n_{0}$ в стекле по уровню люминесценции на длине волны 1540 нм, то необходимо найти связь между суммарной концентрацией ионов эрбия $n_{0}$ и концентрацией ионов в возбужденном (метастабильном) состоянии $n_{2}$, поскольку интенсивность люминесценции пропорциональна последней. Определим установившуюся концентрацию ионов эрбия в метастабильном состоянии.

Рассмотрим трехуровневую схему ионов эрбия (рис. 1). Накачка с длиной волны 980 нм переводит атомы эрбия на третий уровень. Далее происходит быстрая безызлучательная релаксация ионов эрбия на второй уровень, который является метастабильным. Время жизни второго уровня относительно перехода на первый уровень сравнительно велико и составляет $\tau_{21}=0,012$ с [1], что позволяет достигать высоких уровней накачки эрбия. Процесс $2 \rightarrow 1$ является лимитирующей стадией релаксации ионов эрбия в основное состояние 1 , поскольку время $\tau_{21}$ значительно больше времени $\tau_{32}$ безызлучательной релаксации, поэтому установившейся концентрацией ионов эрбия в состоянии 3 можно пренебречь.

В итоге скорость изменения концентрации ионов эрбия в метастабильном состоянии равна сумме скоростей двух процессов: возбуждения $1 \rightarrow 3$ и распада $2 \rightarrow 1$. Скорость процесса $1 \rightarrow 3$ пропорциональна как концентрации ионов в основном состоянии $n_{1}$, так и интенсивности излучения в сердцевине преформы $I_{\text {серд }}$ на длине волны 980 нм. Скорость спонтанного перехода $2 \rightarrow 1$ пропорциональна 


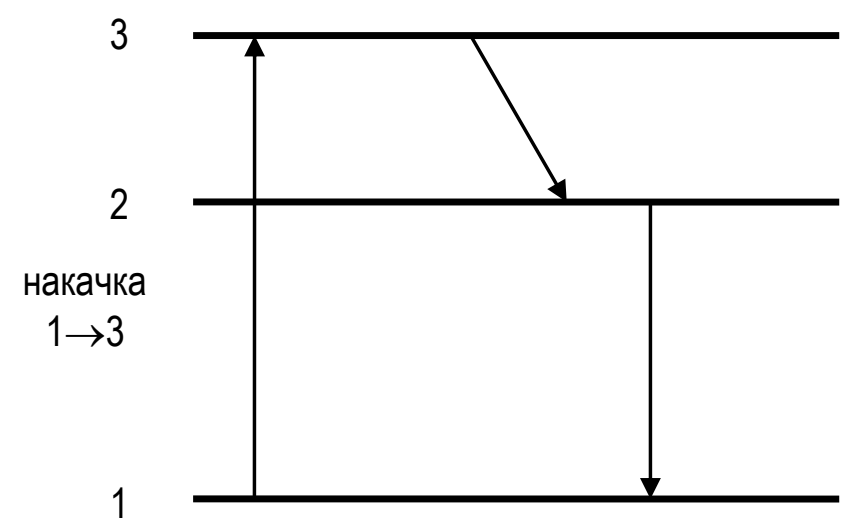

\section{быстрая \\ безызлучательная \\ релаксация \\ $3 \rightarrow 2$}

лазерное излучение

$2 \rightarrow 1$

Рис. 1. Схема уровней иона $\mathrm{Er}^{3+}$

только концентрации ионов эрбия на метастабильном уровне $n_{2}$.

Таким образом, получим:

$$
\frac{d n_{2}}{d t}=k_{1} I_{\text {серд }} n_{1}-k_{2} n_{2},
$$

в установившемся режиме

$$
\frac{d n_{2}}{d t}=0 .
$$

Тогда из (1), с учетом того, что сумма концентраций на первом и втором уровнях равна общей концентрации ионов эрбия, т.е. $n_{1}+n_{2}=n_{0}$, получим

$$
n_{2}=\frac{\alpha n_{0}}{\alpha+1}
$$

где коэффициент

$$
\alpha=\frac{k_{1} I_{\text {серд }}}{k_{2}} .
$$

Из формул $(2,3)$ следуют выводы:

1) концентрация ионов эрбия в возбужденном состоянии прямо пропорциональна суммарной концентрации ионов эрбия;

2) интенсивность люминесценции, прямо пропорциональная $\mathrm{n}_{2}$, будет прямо пропорциональна и концентрации ионов эрбия $n_{0}$;

3) степень насыщения метастабильного уровня 2 (по сути, величина коэффициента $\alpha)$ не зависит от концентрации ионов эрбия в том или ином сечении, а определяется только интенсивностью излучения.

При $\alpha<<1$ формула (2) переходит в формулу

$$
n_{2}=\alpha n_{0} .
$$

Формула (4) показывает, что в рассматриваемом случае физический смысл коэффициента $\alpha$ - доля или степень насыщения метастабильного уровня 2. Так как интенсивность люминесценции прямо пропорциональна $n_{2}$, а коэффициент $\alpha$, согласно (3), прямо пропорционален ин-

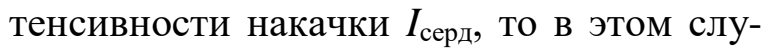
чае интенсивность люминесценции будет пропорциональна мощности накачки.

Можно рассмотреть и другой предельный случай, когда $\alpha>>1$. Тогда из формулы (2) последует

$$
n_{2}=n_{0} .
$$

При этом практически все ионы эрбия будут находиться в метастабильном состоянии. Этот случай соответствует насыщению метастабильного состояния и просветлению заготовки.

Покажем, что при мощностях накачки несколько единиц Вт реализуется режим, очень далекий от насыщения метастабильного уровня ионов эрбия, т.е. $\alpha<<1$, заготовки. Константа $k_{2}$ представляет собой вероятность распада иона эрбия за 1 с. Она равна обратному времени жизни ионов эрбия:

$$
k_{2}=\frac{1}{\tau_{21}} .
$$

Найдем выражение для коэффициента $k_{1}$. Произведение коэффициента $k_{1}$ на 
интенсивность света $I$ представляет собой по смыслу величину, равную вероятности поглощения накачки одним атомом за 1 c, или, другими словами, равную обратному времени процесса поглощения накачки атомом $\tau_{13}$ :

$$
k_{1} I_{\text {серд }}=\frac{1}{\tau_{13}} .
$$

Мощность, поглощаемая атомом эрбия,

$$
P=\frac{h v_{13}}{\tau_{13}} .
$$

С другой стороны,

$$
P=I_{\text {серд }} \sigma_{13} \text {. }
$$

Из формул (6), (7) и (8) следует:

$$
k_{1}=\frac{\sigma_{13}}{h v_{13}} \text {. }
$$

Подставляя (5) и (9) в (3) получим

$$
\alpha=\frac{k_{1} I_{\text {серд }}}{k_{2}}=\frac{\sigma_{13} \tau_{21} I_{\text {серд }}}{h v_{13}} .
$$

Энергия фотона накачки

$$
\begin{aligned}
& h v_{13}=\frac{h c}{\lambda_{13}}=\frac{6,63 \cdot 10^{-34} \cdot 3 \cdot 10^{8}}{0,98 \cdot 10^{-6}}= \\
& =20,3 \cdot 10^{-20} \text { Дж. }
\end{aligned}
$$

Значение сечения поглощения ионов $\mathrm{Er}^{3+}$ в германо-алюмосиликатных стеклах на длине волны накачки 980 нм хорошо известно и составляет $\sigma_{13}=2 \cdot 10^{-25} \mathrm{M}^{2}$ [5].

Интенсивность излучения в сердцевине при мощности излучения накачки $P \sim 1$ Вт и характерном радиусе сердцевины $R_{\text {серд }}=0,75$ мм составит:

$$
I=\frac{1}{\pi \cdot\left(0,75 \cdot 10^{-3}\right)^{2}} \approx 0,57 \cdot 10^{6} .
$$

Тогда для степени насыщения получаем

$$
\alpha=\frac{2 \cdot 10^{-25} \cdot 0,012 \cdot 0,57 \cdot 10^{6}}{20,3 \cdot 10^{-20}} \approx 7 \cdot 10^{-3} .
$$

Таким образом, при мощностях накачки порядка $\sim 1$ Вт степень насыщения метастабильного уровня $\alpha<<1$. При этом интенсивность люминесценции будет прямо пропорциональна мощности накачки.

Схема предлагаемой установки для определения абсолютной концентрации эрбия показана на рис. 1. Основная идея облучать заготовку не сбоку, как предлагалось в работах $[2,3]$, а с торца. При этом апертура источника должна быть чуть меньше апертуры заготовки (синуса максимального угла ввода излучения, при котором излучение будет распространяться только по сердцевине и не будет выходить в оболочку).

По мере распространения излучения накачки по сердцевине будет уменьшаться интенсивность накачки, а следовательно, и интенсивность люминесценции. В результате одновременно будут люминесцировать все точки сердцевины, однако интенсивность люминесценции будет уменьшаться с увеличением координаты $z$ (рис. 2). Согласно закону Бугера-Ламберта-Бера интенсивность на-

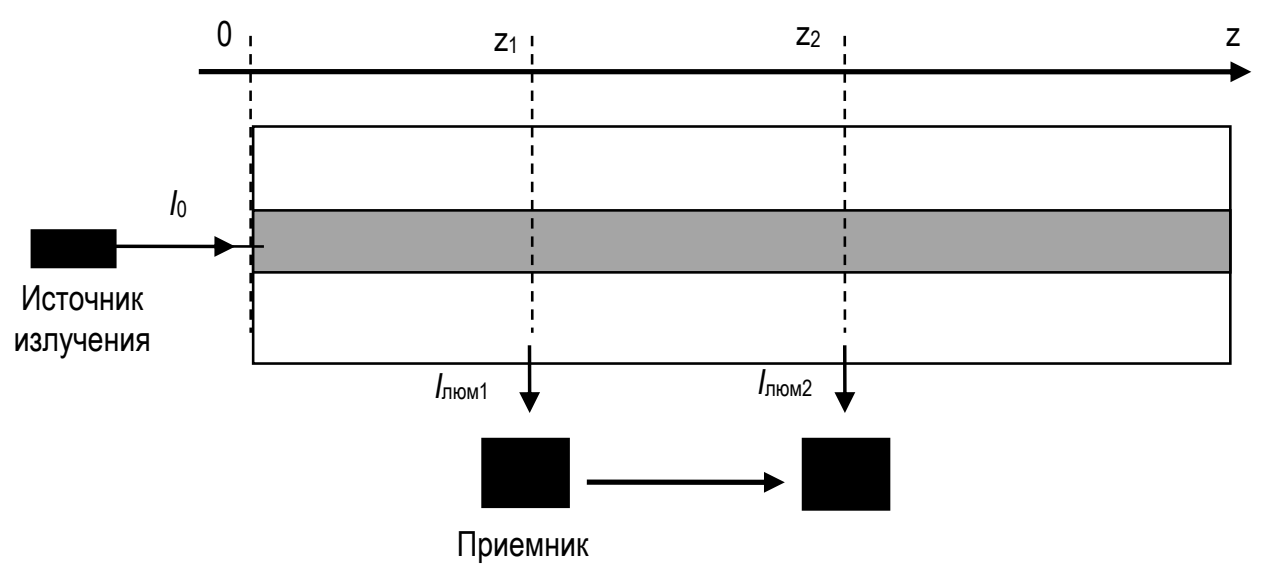

Рис. 2. Схема установки для определения абсолютной концеентрациии ионов $\mathrm{Er}^{3+}$ 
качки в сечениях с координатами $z_{1}$ и $z_{2}$ :

$$
\begin{aligned}
& I_{\text {серд1 }}=I_{0} \exp \left(-\sigma_{13} n z_{1}\right), \\
& I_{\text {серд2 }}=I_{0} \exp \left(-\sigma_{13} n z_{2}\right),
\end{aligned}
$$

где $n$ - концентрация ионов эрбия.

Отношение интенсивностей

$$
I_{\text {серд1 }} / I_{\text {серд2 }}=\exp \left(\sigma_{13} n\left(z_{2}-z_{1}\right)\right) \text {. }
$$

Ранее было показано, что при степени насыщения метастабильного уровня $\alpha<<1$ интенсивность люминесценции прямо пропорциональна интенсивности накачки, т.е. $I_{\text {серд, поэтому }}$

$$
I_{\text {серд1 }} / I_{\text {серд2 }}=I_{\text {люм1 }} / I_{\text {люм2 }} \text {. }
$$

Таким образом $I_{\text {люм1 }} / I_{\text {люм } 2}=\exp \left(\sigma_{13} n\left(z_{2}-z_{1}\right)\right)$, откуда $\quad$ выражаем концентрацию ионов эрбия:

$$
n=\frac{\ln \left(I_{\text {люм1 } 1} / I_{\text {люм } 2}\right)}{\sigma_{13}\left(z_{2}-z_{1}\right)} .
$$

Измеряя приемником величины $I_{\text {люм1 }}$, $I_{\text {люм2 }}$ и расстояние $\left(z_{2}-z_{1}\right)$, можно рассчитать абсолютную концентрацию ионов эрбия.

Приведем некоторые оценки. Отметим, что растворимость лантаноидов в стекле невелика. Для эрбия она по порядку величины составляет $10^{20} \mathrm{~cm}^{-3}$ [4]. Наиболее характерные значения концентрации лежат в диапазоне $5 \cdot 10^{18}-5 \cdot 10^{19} \mathrm{~cm}^{-3}$. Пусть $n=10^{19} \mathrm{~cm}^{-3}=10^{25} \mathrm{M}^{-3}$, тогда на длине $\left(z_{2}-z_{1}\right)=50 \mathrm{~cm}$ (средняя длина заготовки) уменьшение интенсивности люминесценции составит

$$
\begin{aligned}
& I_{\text {люм1 }} / I_{\text {люм } 2}= \\
& =\exp \left(2 \cdot 10^{-25} \cdot 10^{25} \cdot 0,5\right)=e \approx 2,7 .
\end{aligned}
$$

Полученный результат говорит о том, что чувствительность метода достаточно высокая для средних концентраций ионов эрбия. Перемещая приемник вдоль заготовки и измеряя интенсивность люминесценции в различных точках, можно рассчитать среднее значение концентрации между любой парой точек и получить распределение абсолютной концентрации эрбия вдоль образца. Отметим, что измерения для одной пары точек могут занять лишь небольшое время-порядка десятков секунд, в течение которого мощность диода накачки (а следовательно, и интенсивность $I_{0}$ ) можно считать постоянной. При измерениях для другой пары точек мощность диода может быть и другой, поскольку результат зависит лишь от отношения интенсивностей.

\section{Выводы}

Предложен метод измерения абсолютной концентрации ионов эрбия в преформах активных эрбиевых оптических волокон. Показано, что при мощностях накачки сердцевины преформ порядка $\sim 1$ Вт степень насыщения метастабильного уровня $\alpha<<1$ и мощность люминесценции прямо пропорциональна мощности накачки. Метод обладает высокой чувствительностью для характерных значений концентраций ионов эрбия и характерных размеров преформ.

\section{Библиографический список}

1. Курков А.С., Дианов E.M. Непрерывные волоконные лазеры средней мощности // Квантовая электроника. - 2004. - Т. 34. - №2. - С. 881-900.

2. Смирнов А.С., Латкин К.П., Бурдин В.В. Спектроскопический метод измерения однородности концентрации эрбия вдоль длины активной оптической заготовки // Прикладная фотоника. - 2014. № 2. - C. 62-70.

3. Латкин К.П., Смирнов А.С., Константинов Ю.А., Бурдин В.В. Оценка равномерности распределения ионов эрбия вдоль преформы активного оптического волокна по интенсивности люминесценции на разных длинах волн // Вестник ПНЦ. - 2015. - № 3. - С. 4-11.

4. Холодков А.В., Голант К.М., Исхакова Л.Д. Особенности люминесценции $\mathrm{Er}^{+3}$ в легированном галогенами аморфном диоксиде кремния // Тр. ин-та общей физики РАН им. А.М. Прохорова. 2008. - T. 64. - C. 66-80.

5. Desurvire E. Erbium-Doped Fiber Amplifiers, Principles and Applications. - New York: WileyInterscience, 2002. 


\title{
THE ERBIUM IONS ABSOLUTE CONCENTRATION MEASURING TECHNIQUE IN ACTIVE FIBER PREFORM
}

\author{
K.P. Latkin ${ }^{1}$, A.S. Smirnov ${ }^{1,2}$, Yu.A. Konstantinov ${ }^{1}$, V.V. Burdin ${ }^{1,2}$ \\ ${ }^{1}$ Perm Federal Research Center UB RAS \\ ${ }^{2}$ Perm State National Research Polytechnic University
}

Active optical fibers are used as an active medium in optical fiber amplifiers and lasers. The concentration of the active impurity in the core of the fiber is their main characteristic which determines the main parameters of future lasers and amplifiers. The paper proposes the active impurity absolute concentration measuring technique in active fiber perform of an active optical fiber. The technique is based on measuring the luminescence intensity of the active impurity. The technique is considered on the example of an erbium-doped preform. The luminescence exciting radiation has a wavelength of $980 \mathrm{~nm}$ and is directed along the axis of the preform. The luminescence is observed in the spectral region of $1.50-$ $1.55 \mu \mathrm{m}$. The luminescence intensity is recorded from the side surface of the preform. The paper presents a working formula for calculating the absolute value of the concentration of the active element, in particular, erbium ions. The evaluation of the sensitivity of the technique to various concentrations of the active additive is given. The paper also provides some considerations of the technique sensitivity to the stability of the radiation source. These measurements allow us to analyze and control the production process of active optical fibers preforms, to forecast the active impurity concentration and its homogeneity along the fiber produced from the studied perform.

Keywords: erbium, active optical fibers, concentration analysis, preform, optical fiber preform, luminescence spectrum, metrology.

\section{Сведения об авторах}

Латкин Константин Павлович, младший научный сотрудник лаборатории фотоники, Пермский федеральный исследовательский центр УрО РАН (ПФИЦ УрО РАН), 614900, г. Пермь, ул. Ленина, 13А; ассистент кафедры «Общая физика», Пермский национальный исследовательский политехнический университет (ПНИПУ), 614990, г. Пермь, Комсомольский пр., 29; e-mail: latkin.k.p@ya.ru

Смирнов Александр Сергеевич, младший научный сотрудник лаборатории фотоники, ПФИЦ УрО РАН; заведующий учебной лабораторией кафедры «Прикладная математика», ПНИПУ; e-mail: a.s.smrnv@gmail.com

Константинов Юрий Александрович, кандидат технических наук, научный сотрудник лаборатории фотоники, ПФИЦ УрО РАН; e-mail: yuri.al.konstantinov@ ro.ru

Бурдин Владислав Викторович, кандидат физико-математических наук, научный сотрудник лаборатории фотоники, ПФИЦ УрО РАН; доцент кафедры «Общая физика», ПНИПУ; e-mail: vlaburdi@mail.ru 